\title{
A Construct Validity of Investment Decision in the Banking Sector in Libya (A Structural Equation Modeling Approach)
}

\author{
Reda Aburas ${ }^{1}$, Dr. Noor Raihan Ab Hamid ${ }^{2}$ \\ ${ }^{I}$ (Faculty of Business Administration / University Tun Abdul Razak, Malaysia) \\ ${ }^{2}$ (The Dean at the Faculty of Business Administration / UNITAR International University, Malaysia)
}

\begin{abstract}
Investment decision is an important part of strategic decision making. This is because such decision has involves the allocation of money as is known currently over a period of time, in order to make a profit in future and also be subject to different degrees of risk and uncertainty. However, this paper has an objective to validate the measurements of investment decision in the banking sector in Libya. Moreover, this paper provides comprehensive information on the investment decision in Libyan commercial banks, as well as gaining an understanding on the dimensions of customers' decisions to invest. Structural equation modeling using $2^{\text {nd }}$ order CFA was employed to validate the measurements. The findings confirmed financial ability, perceived usefulness, product and company attributes and knowledge and past experiences as dimensions of investment decision. The present study has a fundamental contribution as a role model for the investment decision measurements in Libya.
\end{abstract}

Keywords - Investment Decision, Libyan commercial banks, Construct Validity, Structural Equation Modeling

\section{INTRODUCTION}

The financial industry is witnessing fierce competition from major countries around the world that dominate the world's economy. As such, these countries seek to support these financial institutions so as to be able to have the necessary factors for success, and one of the most important success factors is the acquisition of modern information system. Currently, these financial institutions are in competition with each other and therefore may be in a highly competitive state if there is access to high quality information system [1].

Potential customers will only direct the savings or investments towards capital markets, only if these markets provide credibility and durability that will ensure the highest degree of assurance for such savings to be in good and trusted hands. This in turn will create a granted interest that will achieve returns on these investments. Moreover, the capital markets offer channels and protect revenues for individuals as it is considered the key instrument in promoting economic development worldwide. This can bring about a number of economic benefits, including the benefits of acquisition, possession, use and returns on investments. Capital markets also represent companies that list shares in the stock markets so as to follow the rapid changes in the trading process [2].

This study is important in providing information on the subject of customer's investment decisions. The director general of Computer Systems in the Arab Investment Bank, declared that with the expansion in use of modern technology and the latest tools developed in the banking sector, any branch of a bank that provides traditional banking services is now becoming less important, and will be more likely to lag behind the rest of the competitors.

Hussam [3] stated that there are two dimensions of service quality necessary for improvements in the management of North African banks in general. The first one lies in the improvement and acceleration of services, including access to information for beneficiaries and customers which should be made easily available. The second dimension is the reduction of loads on the banks' management, by developing and providing information services that do not require a concerted, sophisticated effort to be made by the staff of the bank. This dimension is neglected by many despite its great importance. This study also be useful to devise programs, treatment plans, and guidance, in order to achieve a higher quality where the investment decision measurements is concerned and also improve the performance of the banking sector in Libya. Moreover, the results of this study will have a positive effect on both the commercial banks and the stock market in Libya. This study will give a better understanding to the supervisors and CEOs of the commercial banks, on the importance of information service quality in providing better services that boost investment decisions, and thus assist the supervisors and CEOs of the commercial banks in developing a strategic plan associated with the information system and the adoption of new approaches by the commercial banks.

\section{LITERATURE REVIEW}

Banking sectors are essential for the country's economy, since no growth can be achieved unless savings are efficiently channeled into investment. In this respect, the lack of a full-fledged banking sector has 
often been identified as a major weakness of the centrally planned economies. Therefore, reforming the banking sector in many countries around the world and creating a new culture of trust and confidence has been a crucial task in the process of transition into a market economy [4]. Most Governments around the world pay attention to improving reforms and liberating the financial and banking sectors, because of the vital roles these institutions play in enforcing the growth of a balanced and unshaken economy $[4,5]$. During the past years, practical experience improved the ability of the economy to face external crisis. This depended on how strong both the financial and banking sectors were because of the huge contributions in raising the efficiency of the economy in order to achieve stability. Due to the strong and outstanding banking sector of markets and institutes with excellent instruments were mobilized with local assets and were assembled in the form of credits and investments. These instruments were then directed towards the economic sectors and the activities especially indicated extra benefits and brought in more profits. This sector would also be able to attract foreign investment funds in order to provide more funds to cover the local development needs [6]. One of the most important objectives of the banking sector which focuses on the customer is to meet all the needs of the customer. However, in order to compete successfully, and establish loyalty, an enterprise can maintain customer satisfaction by continually improving and developing new and better services as customer satisfaction is dynamic and changes with time [7].

\subsection{Banking Sector Environment in Libya}

The banking sector in north Africa has for long time been rather challenging because the local banks are often unstable and use traditional information service methods. This has resulted in the government and the industries to rely on international banks [8]. The North African government has regulated heavily the banking sector and has imposed strict limits on international competition. In recent decades, the reforms in the banking sector have become the priority of the IMF and the World Bank. One important improvement was in obtaining permission for the increased presence of foreign banks. For example, Egypt has been most successful in attracting local operations of the foreign banks. The manual systems applied by most of the banking sector in the North African countries are barriers to operational efficiency, as well as information service quality. It also slows down trading and information production of these banks. It is important that the North African banks adopt fast automation and electronic information systems in order to attract more customers. They will then have the trust and satisfaction in the information service of the banking sector of these countries [8]. The Libyan authorities have begun to liberalize the national banking sector in the mid-1990s by permitting private ownership of banks. This was introduced only since 2001 with the liberalization of foreign trade that allowed banks to experience substantial changes in the banking system. Foreign interests in the Libyan banking sector is growing and developing every year. Currently, commercial banks account for a tiny proportion of banking activities while the private companies access to credit remains severely restricted. Therefore initiating new systems with more flexibility for the Libyan customers is an essential need [9].

\subsection{Investment Decisions}

According to Anthony and Mustafa [10], the decision to invest is not just a mathematical selection of expected returns on various risk profiles but a whole range of factors- such as political, economic, social etc. These factors could have a profound effect on investment decisions. Tarek [11] has further emphasized the classification of investments into two groups mainly the financial and the non-financial. The former refers to the concept of interest bearing or dividend yielding assets such as stocks, bonds, shares and other forms of securities that are traded in the stock market. The latter group refers to what is generally described as real investments that usually come in the physical form e.g. buildings, equipment and machinery. Some theories have been put forward so as to enhance the comprehension of the characteristics of investment behaviour and performance. One of these theories places emphasis on the influence of financial factors in two dimensions, the first the theory is of profit developed by Sharpiro. This theory sees profit (especially undistributed refrained earnings) as a source of internal fund for financing investment. It defines investment as a function of profits, which depends on the level of corporate income or earnings.

Andersen [12] described decision making as a human cognitive process which leads to a course of action among a set of choices making a decision involves choice which can be an action or an opinion. In the context of modeling investment decision making in finance, by far, a majority of models assume that decision making is a reasoning process which is rational [12]. The investment decision involves looking towards the acquisition of a product or service. This does not usually involve any costs undertaken by the customer and can turn this decision into an effective demand when combined with the ability to invest [13]. The investment decision means that there is the tendency to secure future benefits by dealing with money to make profits and to release money within a specific period of time in order to obtain future cash flow. Should the customer get to financial culpability, then the intention to invest does not mean real investment unless the customer has 
adequate financial capability. Everyone wants to invest, but the capability to invest varies from one person to another.

As investment means looking into the future an investment decision always works without full assurance. The investment decision would be meaningless and worthless if the decision exists in the presence of the possibility of no losses occurring at all. However, the reality of the situation points to the lack of knowledge and the difficulty to accurately determine the returns on the investment. There are two sides to this. According to Al-Balat [13], decision made by the customer involves to how, when, where and how much capital will be spent on investment opportunities. This decision is often followed after research has been conducted to determine costs and returns for each option. In investment decision making in the stock market, especially in the banking sector, stocks and all types of investment, time and risks are critical variables to be considered. Akintoye [14] is of the view that decisions on investment, which takes time to mature, have to be based on the returns which that investment will make. If the investment is unprofitable in the long run, it will be unwise to invest. It would be good to know what the present value of the future investment will be, or how long it will take to mature (give returns). It could be much more profitable to put the planned investment money into the bank and earn interest, or invest in an alternative project.

In fact, there are many factors that cause customers to invest and this has been referred to by both [15, 16]. The investment decision comes from a desire to make a profit, as it drives the customer forward. Profit is attained when an individual sells the share at a higher price than the price at which it was bought. This is a strong and influential factor that encourages many people to play a significant role in the areas of investment, in the hope of getting positive results and profits. Investments forecast such circumstances and the interest rates involved in the investment decisions [13]. There are other factors that increase

the incentive to invest, as referred to by [11, 17] Such studies are of the view that by providing a high degree of investment awareness, together with the provision of economic, social and the political climate that is suitable for investment, perhaps the most important aspect of this climate is the existence of laws that protect the customers as well as the investments. In addition, the atmosphere of economic stability, political reassurance, and the multiplicity of investment tools provide a wide variety of investment opportunities.

Previous studies have shown that the demographic factors play a great role in the investment decision $[18,19]$. The investment decision depends on many demographic factors that influence the customer's investment decision and the customers' selection of investment tools such as income, age, gender, experience, educational level, as well as identifying investment objectives and the social situation. Investment culture varies from one person to another, each according to the knowledge of financial matters and investment. Based on this, culture may affect the behaviour of the customer who in turn is usually affected by the culture of the society. Societies promoting development and investments are always having special morals, behavioural values in addition to good knowledge. These attributes enable them to progress and develop through the promotion of values among the members of the community. On the other hand, those communities that have hostile values for knowledge and development, including investments, will progress for but lag in development [20].

The theory of supply and demand is one of the oldest economic theories, and perhaps one of the most fundamental concepts of economics. It can be considered as one of the main factors affecting risk behaviour, the stock market, share prices and securities. Supply refers to the ability of providing company shares on the market for sale to customers who have intentions of purchasing. The source of these shares is the company that puts such shares up for sale /trading on the stock market. The term "demand" refers to the intention and the ability to buy shares. The term demand can also be defined as the number of shares customers wish to buy at a time when such shares are put up for sale. The relation between supply and demand is a directly proportioned relationship. In other words, any increase in demand will lead to an increase in the volume of supply, but if the source of shares does not respond to this demand, then an increase in the value of the shares is imminent. Therefore, supply and demand does affect investment decision [21].

\subsection{Dimensions of Investment Decision}

The investment decision, as any other type of decisions, requires basic dimensions to be successful in the short and long run. However, there are a various elements which affect the customer's process decisionmaking and the final investment decision. This study concentrated on four dimensions of investment decisions; the dimensions are discussed below:-

\section{i. Financial ability}

The financial ability of an individual is the most important requirement in order to part in the investing process in the stock market. The investment decision in the stock market reflects the desire to acquire a company's stocks or shares offered for trade. More often than not, the investment decision is not associated with any possible or potential cost paid by the customer. The intention might lead to a transformation of an active demand when connected with the ability to purchase. The active demand is the intention to acquire stocks which 
is linked to financial ability. Hence, the active demand has two elements; the intention to acquire stocks and the financial ability to buy stocks [22].

\section{ii. $\quad$ Perceived usefulness}

The study of risk behaviour is based on the basic assumption that a customer is a rational person who intends to maximize the benefits by investing, with the aim of achieving the maximum satisfaction possible. Therefore, a customer will look for opportunities to maximize profits or benefits, which mean that there are basic requirements in starting the investment process [23]. For example, the existence of clear economic policies will motivate a potential customer to increase the investment. Profit is one of the most important determinants of investment, and the desire to increase ones profit earnings will increase the desire to invest, which leads to making an investment decision. A decrease in profit can cause a postponement in making an investment. In addition, there are many factors that affect the customer, which can influence the investment decision, such as market stability, the efficiency of management, and the reputation of the market monitoring administration [15]. Information technology used in or by banks and the role of technology in business and finance, play an important role in motivating customers to invest by providing advanced banking services via electronic channels which are easily accessible, safe and feature diversity which enables customers to conduct banking transactions more conveniently. Furthermore, it is more comfortable and safer to use an internet banking website (Web) of a bank, as well as phone banking (IVR). Such services, along with ATM machines, internet mobile banking (WAP), and banking information via SMS, are considered to be low cost services that give the customers of the bank the opportunity to access accounts and related information 24 hours a day, seven days a week [24].

\section{iii. Products \& Company Attributes}

The customers' decisions are highly affected be it directly or indirectly by the performance of the companies listed in the stock market, as well as the customers' rationale. The customers' rationale has greater prospects for investment, upon receiving the necessary sufficient information about the performance of the listed companies in mind where the potential customer will want to know the achieved and expected profits, as well as the growth rate of the company (assets, rights, capital). Other points of interest about the company will be the company's reputation, and the quality of its products, the efficiency of the company's management, the amount of speculation about the company's shares, as well as the competition faced by the company from its rivals. All this information about the company is important in initiating the process of investment in the stock market [25].

\section{iv. Knowledge \& past experiences}

Investment experience is an important factor influencing behaviour. Customers with more experience have relatively high risk tolerance and as portfolios of higher risk are constructed [26]. The success or failure of past customer experience, influences the tendencies of customers towards risk and risk perception, and further affects decision-making behaviour. Kathleen and Byrne [27] shows that risk and investment experience tend to indicate a positive correlation and past experience of successful investment increases customer tolerance of risk. Inversely, unsuccessful past experience leads to reduced tolerance to risk. Therefore past investment behaviour affects future investment behaviour.

\section{METHODOLOGY}

The unit of analysis in this research is the bank customers of five main commercial local banks in Libya namely Al-Sahara Bank /PNP Paribas Group, Al-Umma Bank, Al-Gumhouria Bank, Al-Wahda Bank and The National Commercial Bank. The respondents are the customers were obtained from previous mentioned banks that operated in four most highly populated cities in Libya: Tripoli, Benghazi, Al Jabal Garbi and Al Akhdar. A total number of 1000 customers of the aforesaid banks that had banking accounts and investments in the banking sector in Libya. The customers were randomly selected using judgment sampling technique for the sampling method; each participating bank was allocated with 200 questionnaires whereby and the questionnaires will be given to the customers who visit the banks at 2 cluster times i.e. $9.30 \mathrm{am}, 1.00 \mathrm{pm}$. The self administered questionnaires were returned in a collection box once the customers responded, 785 cases (respondents) were used for further analysis such as confirmatory factor analysis, $2^{\text {nd }}$ order CFA, measurement model, structural model.

This research is conducted through self administered questionnaire whereby the questionnaire consisted of two sections. The target questions focus on the all variables of the study such as investment decision (35 items to measure the 4 constructs). The scaling used in this research is the 5-point Likert scale of 1-strongly disagree, 2-disagree, 3-neutral, 4-agree and 5-strongly agree. All measures were adapted and modified from [28] the demographic variables asked are gender, age, education and monthly income of the respondent. The data were input into SPSS version 20 software program and analyzed using AMOS version 20. Several statistical validity tests and analysis were conducted such as reliability test and composite reliability tests, validity tests 
using confirmatory factor analysis for construct validity, discriminant validity for multicollinearity treatment, descriptive analysis, correlation and structural equation modeling analysis using AMOS 20.0.

\section{FINDINGS}

\subsection{Reliability of the Measurements}

All variables were subjected to reliability analysis to assess the dimensionality of the measurement scale. Cronbach's alpha was used to determine the internal consistency of the measurement scale. The test results show that all measures or cases exhibited high reliabilities which exceeded the acceptable level of .70 [29]. These results are given in Table 1. Using Cronbach's alpha indicators, the present study found Investment Decision fulfills the criteria of reliable of measurements. The purpose of the reliability testing was to examine the properties of measurement scales and the items in order to obtain the overall index of internal consistency of the scales by excluding problematic items [29].

Table 1: Reliability of the Measurements

\begin{tabular}{|c|c|c|c|}
\hline Dimension(s) & NO & Item(s) of Investment Decision & $\begin{array}{l}\text { Cronbach's } \\
\text { Alpha }\end{array}$ \\
\hline \multirow{3}{*}{$\begin{array}{c}\begin{array}{c}\text { Financial } \\
\text { ability }\end{array} \\
\alpha=0.834\end{array}$} & Q2 & I have the financial ability to buy stocks. & 0.863 \\
\hline & Q22 & $\begin{array}{l}\text { Ease of obtaining borrowed funds to purchase stocks would } \\
\text { influence my investment decision. }\end{array}$ & 0.751 \\
\hline & Q25 & $\begin{array}{l}\text { Procedures to obtain funds are made available by the banks for potential } \\
\text { clients. }\end{array}$ & 0.695 \\
\hline \multirow{11}{*}{$\begin{array}{l}\text { Perceived } \\
\text { Usefulness }\end{array}$} & Q3 & The existence of clear economic policies by the government. & 0.894 \\
\hline & Q4 & The banking services are useful. & 0.887 \\
\hline & Q5 & $\begin{array}{l}\text { The issuance of shares is subject to a specified period of time; therefore it } \\
\text { affects my investment decision. }\end{array}$ & 0.892 \\
\hline & Q8 & I need to diversify my investments. & 0.896 \\
\hline & Q9 & The nominal value of the shares is relatively low. & 0.890 \\
\hline & Q10 & The financial market is stable. & 0.893 \\
\hline & Q12 & $\begin{array}{l}\text { The availability of a large number of advisors and financial analysts in the } \\
\text { stock market will influence my investment decisions. }\end{array}$ & 0.887 \\
\hline & Q14 & $\begin{array}{l}\text { The existence of a large number of customers in the stock market will } \\
\text { influence my investment decision. }\end{array}$ & 0.880 \\
\hline & Q24 & $\begin{array}{l}\text { Friends or coworkers recommendations will influence my investment } \\
\text { decision. }\end{array}$ & 0.928 \\
\hline & Q24 & Recommendations from my broker will influence my decision to invest. & 0.893 \\
\hline & Q26 & The existence of clear economic policies by the government. & 0.894 \\
\hline \multirow{10}{*}{$\begin{array}{l}\text { Product- } \\
\text { Company } \\
\text { Attributes }\end{array}$} & Q11 & $\begin{array}{l}\text { The efficiency of the management team will prompt me to invest in the } \\
\text { banking sector. }\end{array}$ & 0.869 \\
\hline & Q13 & The listed companies are high performers. & 0.893 \\
\hline & Q15 & Information about company shares offering is transparent. & 0.895 \\
\hline & Q16 & $\begin{array}{l}\text { The management structure of the company is an important consideration } \\
\text { in making my decision. }\end{array}$ & 0.871 \\
\hline & Q17 & The reputation of the governing authority is critical to me. & 0.873 \\
\hline & Q18 & My investment decision is influenced by the expected corporate earnings. & 0.878 \\
\hline & Q19 & Past performance of the firm's stock affects my investment decisions. & 0.880 \\
\hline & $\mathrm{Q} 20$ & The reputation of a firm plays a vital role in my investment decisions. & 0.872 \\
\hline & Q21 & The perceived ethics of the firm also influences my investment decision. & 0.921 \\
\hline & Q23 & $\begin{array}{l}\text { The reputation of the firm's shareholders also plays an important role in } \\
\text { my decision making. }\end{array}$ & 0.871 \\
\hline \multirow{3}{*}{$\begin{array}{l}\text { Customers } \\
\text { experience } \\
\alpha=0.858\end{array}$} & Q1 & I have good knowledge of stocks. & 0.694 \\
\hline & Q6 & I can predict the financial risks in the banking sector. & 0.684 \\
\hline & Q7 & The price of stock is speculated to be very high in the future. & 0.974 \\
\hline
\end{tabular}

\subsection{CFA of Investment Decision Dimensions}

\section{i. Measurement Model of Financial ability}

Measurement model of financial ability was conducted using CFA. This section presents a unidimensional model of financial ability (Fig 1). The model consists of three observed variables. Its reliability level, standardized regression weights and goodness-of-fit statistics are displayed in Fig 1. Support for convergent validity is evident from the factor loadings, where all items exceeded 0.60 and these items appeared to be reliable measures of financial ability based on its internal and validity of items in the hypothesized model. Furthermore, for the CFA of financial ability, the CFI and TLI does not appear with their value because of the indication as saturated model [30] or perfect fit $(\mathrm{GFI}=1)$. Based on the values of standardized regression weights, reliability and goodness-of- fit statistics, the measurement model of finance fitted the data well. The three-indicator model is illustrated in Fig 1. 


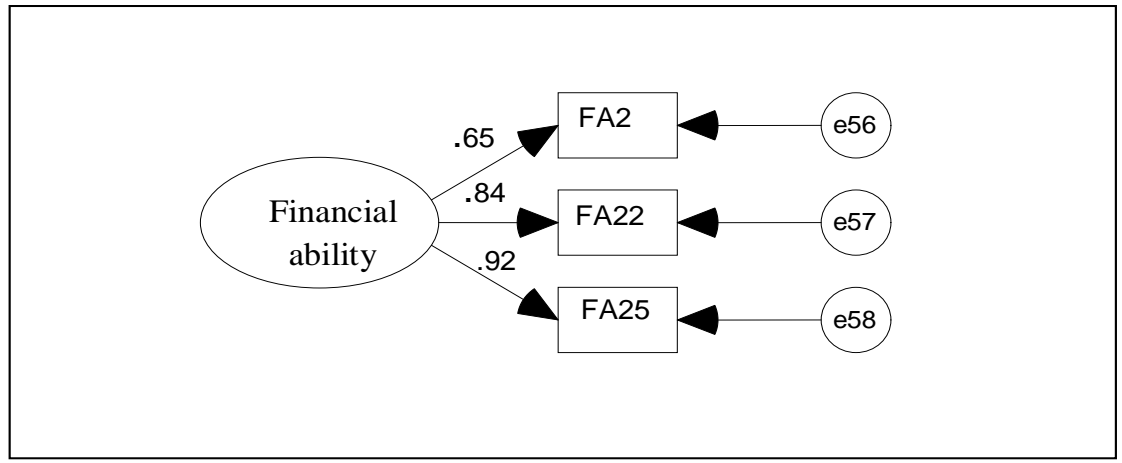

Fig 1: Measurement model of financial ability

Table 2: Goodness-of-fit Statistics for the Measurement Model of Financial

\begin{tabular}{|ll|}
\hline Standardised Regression Weight & Estimate \\
& \\
FA2 $\leftarrow$ FINANCIAL ABILITY & 0.65 \\
FA22 $\leftarrow$ FINANCIAL ABILITY & 0.84 \\
FA25 $\leftarrow$ FINANCIAL ABILITY & 0.92 \\
\hline Keys: & \\
Finance & \\
FA2 - I have the financial ability to buy stocks. & \\
FA22 - Ease of obtaining borrowed funds to purchase stocks would influence my & \\
$\quad$ investment decision. & \\
FA25 - Procedures to obtain funds are made available by the banks for potential \\
clients.
\end{tabular}

\section{ii. Measurement Model of Perceived Usefulness}

The results showed a very good fit of the data to the model. The internal reliability is very good indicating high internal reliability and consistency. In addition, the goodness-of-fit statistics: RMSEA $=0.000$; $\mathrm{CFI}=0.996$, TLI $=0.994$ indicating a good fit and $\mathrm{GFI}=0.998$, also indicates a good fit. Based on the values of standardized regression weight, reliability and goodness-of-fit statistics, the measurement model of the perceived usefulness fit the data well.

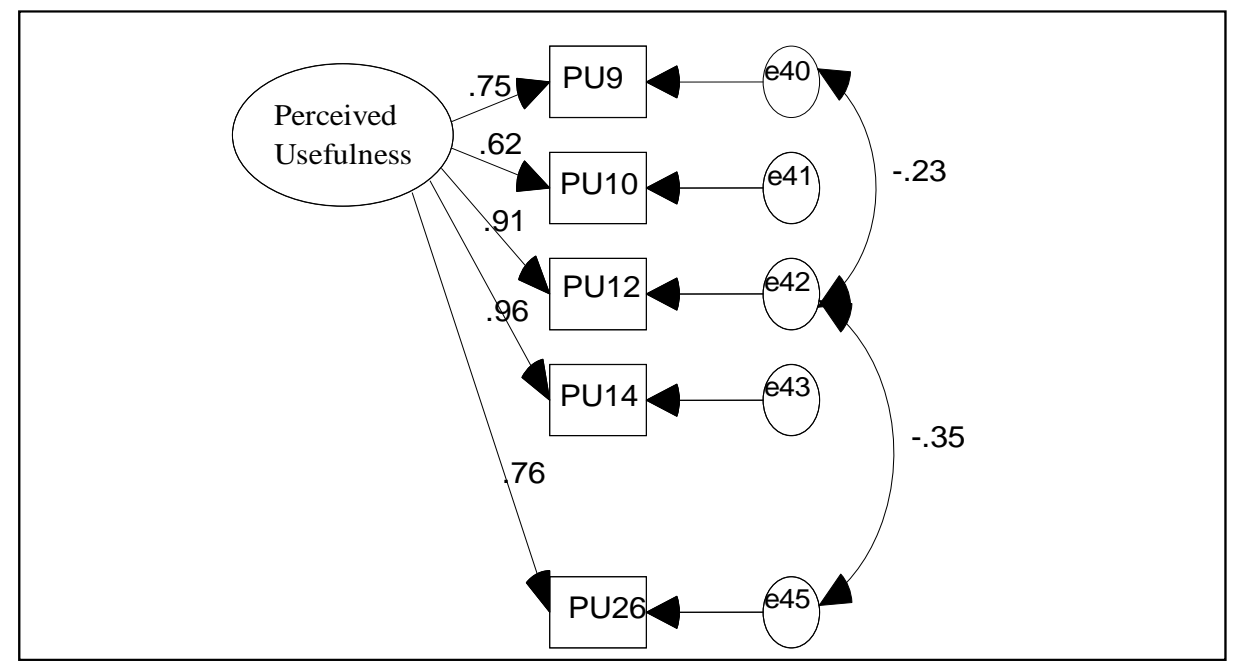

Fig 2: Measurement model of Perceived Usefulness 


\section{Table 3: Goodness-of-fit Statistics for the Measurement Model of Perceived Usefulness}

\begin{tabular}{|c|c|c|c|}
\hline Standardised Regression Weight & Estimate & Goodness-of-fit measures & \\
\hline PU9 $\leftarrow$ USEFULNESS & 0.75 & Root mean error of est.(RMSEA) & 0.00 \\
\hline PU10 $\leftarrow$ USEFULNESS & 0.62 & Goodness-of-fit index(GFI) & .99 \\
\hline PU12 $\leftarrow$ USEFULNESS & 0.91 & Tucker-Lewis index(TLI) & .99 \\
\hline PU14 $\longleftarrow$ USEFULNESS & 0.96 & Comparative Fit index(CFI) & .99 \\
\hline PU26 $\leftarrow$ USEFULNESS & 0.76 & & \\
\hline $\begin{array}{l}\text { Keys: } \\
\text { USEFULNESS - }\end{array}$ & & & \\
\hline $\begin{array}{l}\text { PU9 - The nominal value of the shares is } \\
\text { relatively low. }\end{array}$ & & $\begin{array}{l}\text { PU14 - The existence of a large } \\
\text { number of customersin the stock }\end{array}$ & \\
\hline PU10- The financial market is stable & & market will influence my & \\
\hline $\begin{array}{l}\text { PU12-The availability of a large number of } \\
\text { advisors and financial analysts in the } \\
\text { stock market will influence my } \\
\text { investment decisions }\end{array}$ & & $\begin{array}{l}\text { investment decision. } \\
\text { PU26 - Recommendations from my } \\
\text { broker will influence my } \\
\text { decision to invest. }\end{array}$ & \\
\hline
\end{tabular}

\section{iii. Measurement Model of Product}

The uni-dimensional model of product construct is presented in this section. Initially, the measurement model consisted of 10 observed variables. However, 5 items: PA11, PA13, PA15, PA18, PA21 were eliminated in order to reach a significant model that fits well with the data. Having done omitting low loading items, the internal reliability was found to be very good, with the support of the convergent validity. The good-of-fit statistics of this model, as shown in Table 4 are reinforced by RMSEA $=0.036$, CFI $=0.99$, TLI $=0.99$ and GFI $=0.99$. Therefore, this study proposes a five -indicator model of product construct as illustrated in Fig 3 .

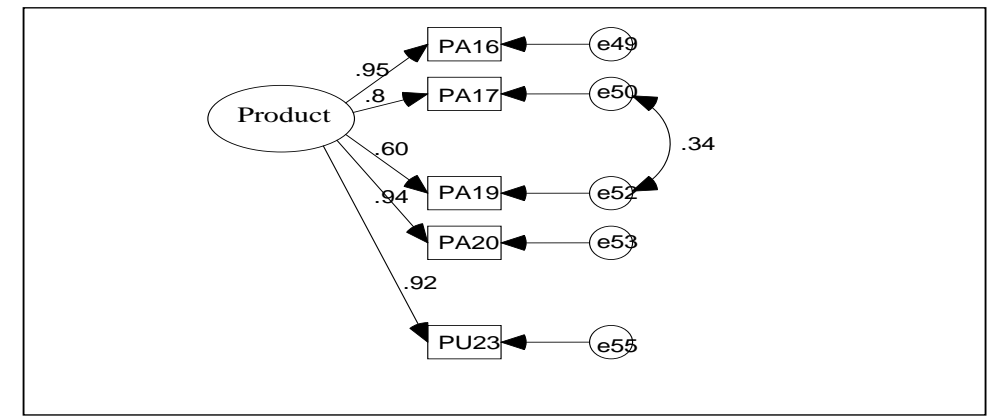

Fig 3: Measurement model of Product

\section{Table 4: Goodness-of-fit Statistics for the Measurement Model of Product}

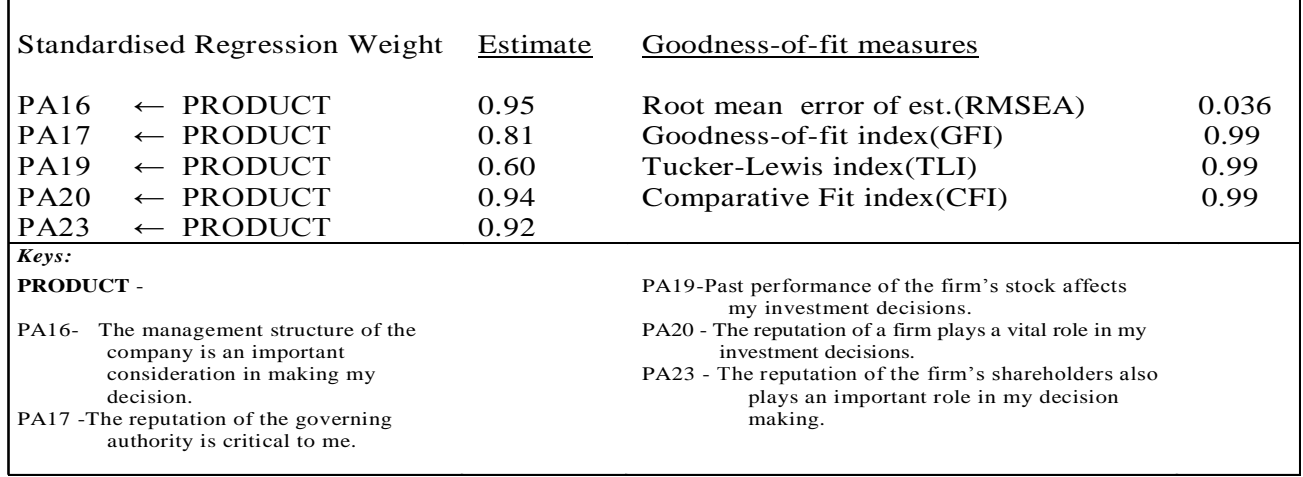

\section{iv. Measurement Model of Customers Experience}

Measurement model for CFA of Customers Experience was conducted using confirmatory factor analysis. This section presents a unidimensional model of customer experience. The model consists of 3 observed variables. Its reliability level, standardized regression weights and goodness-of-fit statistics are displayed in Table 5. Support for convergent validity is evident from the factor loadings, where all items exceeded 0.50 and these items appeared to be reliable measures of customers experience based on its internal 
reliability and validity of the indicators. The CFI, TLI also does not appear with the values and GFI value is equal to 1.0 indicating a perfect fit. Furthermore, the value of CFI and TLI does not appear because of the saturated model of hypothesized model. The perfect fit of the model confirmed the significant measurements of customer experience. Based on the values of standardized regression weights, reliability and goodness-of- fit statistics, the measurement model of customers experience fitted the data well.

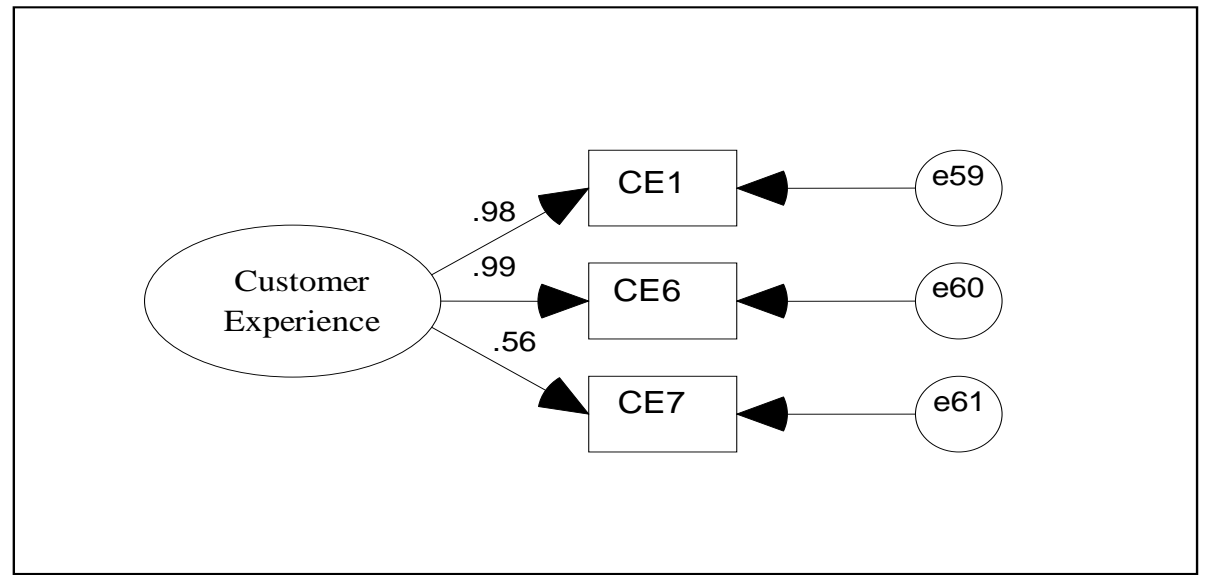

Fig 4: Measurement model of Customers Experience/ Knowledge

Table 5: Goodness-of-fit Statistics for the Measurement Mode of Customers Experience

\begin{tabular}{ll} 
Standardized Regression Weight & Estimate \\
CE1 $\leftarrow$ CUSTOMERS & 0.98 \\
CE6 $\leftarrow$ CUSTOMERS & 0.99 \\
CE7 $\leftarrow$ CUSTOMERS & 0.56 \\
\hline Keys: & \\
Customers Experience: & \\
CE1 -I have good knowledge of stocks. & \\
CE6 - I can predict the financial risks in the banking sector. & \\
CE7 - The price of stock is speculated to be very high in the future. & \\
\hline
\end{tabular}

\subsection{Measurement Model of Investment Decision ( $2^{\text {nd }}$ Order Analysis)}

Furthermore, measurement model of Investment decision dimension configured using the $2^{\text {nd }}$ order CFA. This section presents a unidimensional model of investment decision. Initially, this model contained four dimensions. All the four dimensions of investment decision have been identified in the literature review. These dimensions are financial ability, perceived usefulness, products/company attributes and past customers experiences. Table (6) determines and presents the fit measures for this four-dimension model. All the factor loadings of more than 0.60 provide support for this model. Further, internal reliability and consistency are evident from convergent validity of the measurements (Factor Loading > 0.5) which indicate that the twelve item model is a good measure of the investment decision construct. Table (6) confirmed the four dimensions of investment decision: financial ability (factor loading $=0.843$ ), perceived usefulness (factor loading $=0.892$ ), product (factor loading $=0.837$ ) and customer (factor loading $=0.775$ ).

The fit indices: $\mathrm{P}$-Value $=0.291 ; \mathrm{RMSEA}=0.017 ; \mathrm{CFI}=0.996, \mathrm{TLI}=0.994$ and $\mathrm{GFI}=0.981$, indicates a good fit. Based on the values of standardized regression weights, reliability and goodness-of-fit statistics, the measurement model of investment decision fitted the data well. The twelve -indicator model of investment decision is illustrated in Fig (5). Also it has shown the allowing of error terms to be correlated as gives a better fit to the model. 


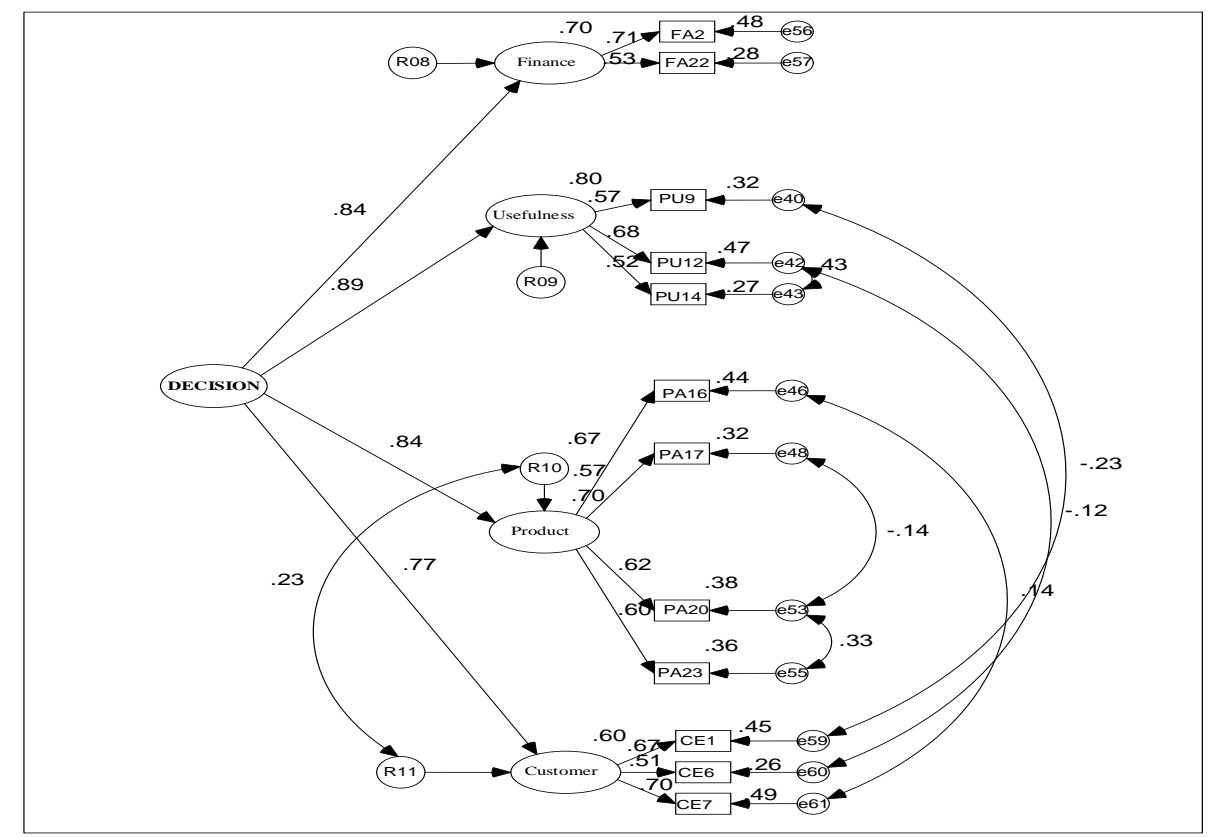

Fig 5: Measurement Model of Investment Decision

Table 6: Measurement Model of investment decision ( $2^{\text {nd }}$ Order Analysis)

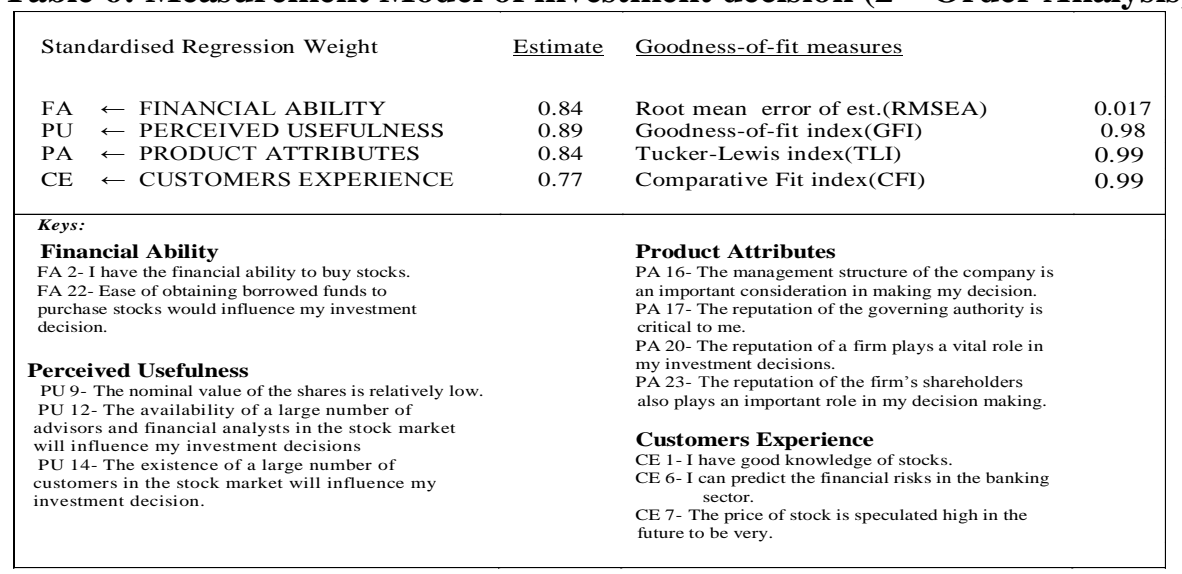

The positive correlation between the error terms (e46 and e61), (e53 and e55) and (e42 and e43) are theoretically and empirically justified. Theoretically, when the management structure of the company is very good, well organized and the top managements are careful about increasing the value of the company's shares (e46); the price of the stock in such company is speculated to be very high (e61) [22, 13]. Moreover, since positive and strong reputation of the company and shareholders (e53) may be a manifestation of a positive attitude toward the role of investor's decision making $(\mathrm{e} 55)[22,20]$. On the other hand, the negative correlation between (e48 and e53) theoretically illustrates that; the reputation of the governing authority would be critical (e48) and lead to a negative attitude toward investment. Both (e42, e43 and e60) are error terms for measures of the influence on the investment decision and predicting the financial risk in the banking sector by the availability of a large number of advisors, financial analysts, and the existing customers in the stock market. Likewise, the negative correlation between (e40 and e59) is also theoretically and empirically justified. Theoretically, the good knowledge and experience in knowing the stock, the share types and values (e40), would influence the investor to buy shares based on the nominal values (e59).

\subsection{Goodness of Fit Indexes}

Confirmatory factor analysis was conducted on every construct and measurement models (see Table 7). All CFAs produced a relatively good fit as indicated by the goodness of fit indices such as CMIN/df ratio $(<2)$; Goodness of Fit Index (GFI) of $>.95$; and root mean square error of approximation (RMSEA) of values less than $.08(<.08)$. 
Table 7: Goodness of $1^{\text {st }}$ order and $2^{\text {nd }}$ order CFA of Measurement Model

\begin{tabular}{|c|c|c|c|c|c|c|c|c|c|}
\hline \multirow{2}{*}{ Variable(s) } & \multirow{2}{*}{ Dimensions } & \multicolumn{8}{|c|}{ Goodness of Fit Indexes } \\
\hline & & $\mathbf{X}^{2}$ & DF & Ratio & $\mathbf{P}$ & GFI & CFI & TLI & RMSEA \\
\hline \multirow{5}{*}{$\begin{array}{l}\text { INVESTMENT } \\
\text { DECISION }\end{array}$} & Finance & & & & & & & & \\
\hline & & - & - & - & - & 1.000 & - & - & - \\
\hline & Usefulness & 1.044 & 3 & 0.348 & 0.791 & 0.99 & 0.99 & 0.99 & 0.000 \\
\hline & Product & 8.176 & 4 & 2.044 & 0.085 & 0.99 & 0.99 & 0.99 & 0.036 \\
\hline & Customer & - & - & - & - & 1.000 & - & - & - \\
\hline \multicolumn{2}{|c|}{$2^{\text {nd }}$ Order Investment Decision } & 47.594 & 43 & 1.107 & 0.291 & 0.981 & 0.996 & 0.994 & 0.017 \\
\hline
\end{tabular}

\section{Conclusions and Recommendations}

The present study confirmed the valid model of investment decision in the banking sector in Libya. Detail measurements of the four factors have been validated using $2^{\text {nd }}$ order CFA SEM. However, this study contributes to increase the efficiency of banking sector performance, not only in Libya but also other financial institutions. The finding provides good support for a four-dimension model of investment decision in the knowledge of customer investment decision. Theoretically, this study has contributed to the field of strategy and management, empirically identifying the measurement of investment decision and modeling the multipleconstructs of investment decision which the previous studies lacked. Next, as the research was carried out in Libya, this study has filled the gap in the literature which lacks findings from the North African region. The results of this study indicate that investment decision depends on four dimensions. All the four dimensions of investment decision have been identified in the literature review. These dimensions are financial ability, perceived usefulness, products/company attributes and past customers experiences are key drivers of the Libyan customers' investment decision making process. Thus, sound information service that takes in consideration these four factors is of paramount importance to the performance of Libyan banking sector. Providing information assets customers to choose the best investment alternatives that fit their financial ability are one of the strategies that could be adapted in such a system. Moreover, the study found that to achieve perceived usefulness in the Libyan banks, greater focus on providing a suitable number of advisors and financial analysts in the Libyan stock market could support the customer investment decision in choosing the best alternative. Similar research may be replicated in other North African countries such as Egypt, Algeria, and Middle East Countries such as Saudi Arabia, Yaman, Oman and Jordan since these countries have economic and cultural backgrounds that are similar to Libya. Further studies may examine how culture and diversity influence the perceptions of investment decision. Finally, it is suggested that for future studies, a qualitative approach such as interviews and focus group discussions may add more depth to the findings of the study. The study was conducted in the banking sector. The findings may not reflect the overall situation in other sectors, such as the public sector in Libya. As such, further research should be conducted in other organizational cultures and business environments to determine the generalization of the findings.

Some limitations are related to the type of data collected. All data collected was self-report. It is possible that participants may think and view themselves in a certain way, but their actions or others' observations of them might give a conflicting picture or additional insight into the customers' attitudes. Also, cross-sectional, correlational data was collected. This data can only be used to describe how certain psychological constructs relate at a certain point in time and does not allow for observations of changes over time or for causational conclusions to be reached. The data was also collected primarily from customers as potential user and investors. Due to the specific developmental challenges facing this type of sample, the generalization of the results may be limited to this particular segment of the population.

Furthermore, the present study adopted a quantitative approach both in the design and data analysis. The approach may not be able to translate human's feeling and perceptions. However, the approach used in this study does not invalidate the findings of this study. The quantitative approach is acceptable in subjective measurement. Moreover, reliability tests show that the constructs in the present study possessed an acceptable reliability values. Global models that are available are used as references to construct the research framework and research model; Although this approach might not be able to translate human's feeling or perceptions into numbers. However, this approach is acceptable in subjective measurement. Furthermore, the reliability test results revealed that each constructs in this study had an acceptable value. Therefore, this study suggests that in future research, qualitative approach seems appropriate. A combination of both, quantitative and qualitative approach, such as in-depth interview and focus group discussion may provide strength to the methodology and findings of study. 


\section{Acknowledgements}

I would like to acknowledge and extend my heartfelt gratitude to my supervisor Dr. Noor Raihan $\mathrm{Ab}$ Hamid for the invaluable guidance and support throughout the study.

\section{References}

[1] Al-Marafi, A. (2008). Financial institutions and the missing role. The magazine of Arab Markets. Journal of Finance, $552,1143$.

[2] Sakka, M. (2000). The Role of financial markets in economic activity and privatization program, analysis of stock markets. Arab Planning Institute in Kuwait.

[3] Hussam, M (2002). Technical information is still out of service in most Arab banks, Middle East. International Journal of Arab, 8768.

[4] Al-Jasir, M. S (2002, October). Development of the financial sector to achieve better economic growth: Future Vision for the Saudi economy until (2020). Paper presented at the Ministry of Planning, Riyadh.

[5] Ghassan, I. A and Vaiq, N (1993). The Management of Banks ( ${ }^{\text {st }}$ Ed). Amman: Al Safa publication.

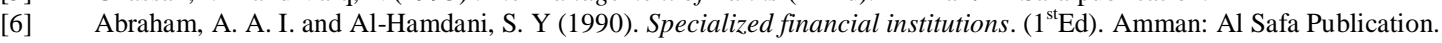

[7] Bloemer, J, Ruyter, K. D. and Peeters, P (1998). Investigating drivers of bank loyalty: the complex relationship between image, service quality and satisfaction. International Journal of Bank Marketing, 16(7), 276-286.

[8] The World Bank (2009) Middle East and North Africa Region (2009) Economic Developments and Prospects Navigating through the Global Recession. Washington, DC

[9] Central Bank of Libya. (2008). Second Annual Report Fifty. Review Final Report. Libya: Central Bank of Libya.

[10] Anthony, E and Mustapha, I (2010). Factor Analysis of Investment Decision in Nigerian Insurance Companies. Interdisciplinary Journal of Contemporary Research in Business, 2(8).

[11] Tarek, A. (1998). Customer's Guide to the Stock Exchange (2 ${ }^{\text {nd }}$ Ed.). Ein Shams: Faculty of Commerce publication.

[12] Andersen, J. V (2008). Models of Investment Decision Making in finance. In Encyclopedia of Complexity and Systems Science. Retrieved from: http://arXiv.org/abs (12 March, 2011).

[13] Al-Balat, A (1996). The determinants of investment behaviour and their relationship to economic and social characteristics of the individual customer, "a field studies in the central region of the Kingdom of Saudi Arabia". Arab Journal of Administrative Sciences, 3(2).

[14] Akintoye, R (1999). Know your capital market, Mc. Lagos, Nigeria: Ezlyon Educational.

[15] Hindi, M. (1999). The Basics of Investment $\left(4^{\text {th }}\right.$ Ed.). Al-Eskandria: University publication.

[16] Al-Hanawy, M. S (2004). The Capital markets and financial institutions ( $\left.1^{\text {st }} \mathrm{Ed}\right)$. Al-Eskandria: University publication.

[17] Al-Shummary, S., Alabaid, A. and Al hamady, N (2005). Management Information Systems, A modern Perspective (1 ${ }^{\text {st }}$ Ed.). Amman: Al-Furqan publication.

[18] Sowlash, S. (1989) Customers Dimensions in the Arab Financial Markets of Jordan, Kuwait, and Egypt. Paper Presented for the financial Accounting conference at the Yarmouk University on December, P.12-14.

[19] Kaplan, S. and Reckers, P (1990). An examination of the effect of the president's letter and stock advisory service information on financial decisions. Behavioral research In Accountancy, 33(3), 11-14.

[20] Al-Ghadeer, H and Asad, R (1999). Customer behaviour and the complete entry. Amman: Zahran.

[21] Sabri, H. N. (1996). Investing in Securities: Introduction to the Fundamental and Technical Analysis. The Book of Al-Ahram Economic, No. 100 .

[22] Obaidat, M. I (1995). Consumer Behaviour, $\left(2^{\text {nd }}\right.$ Ed.). Amman: the future publication.

[23] Davis, F. D (1989). Perceived Usefulness, Perceived Ease of Use, and User acceptance of information technology. MIS Quarterly, 13(3), 319-340.

[24] Al-Musseri, H (2007). The Internet Banking Services. Paper presented at conference of comprehensive internet banking (a future look) Cairo: Ain Shams University.

[25] Mukabalah, S. (2010). The Capital Markets and its Economical Role. Retrieved February

[26] C,2010, fromhttp://www.cma.gov.om/documents/817edae1-fa19-4afa-a532-95bac3ebddb2.ppt 381

[27] Kathleen and Byrne (2005). How do Consumers Evaluate Risk in Financial Products. Financial Services Marketing 10 (1), 21-36

[28] Mogey, N. (March 25, 1999). "So You Want to Use a Likert Scale?" Learning Technology Dissemination Initiative. Heriot-Watt University. Retrieved (April 30, 2009).

[29] Hair, J. F., Black, W.C., Babin, B. and Anderson, R.E (2010). Multivariate data analysis. (7 $7^{\text {th }}$ Ed.). Prentice Hall, Upper Saddle River: New Jersey.

[30] Byrne, B.M (2010). Structural equation modeling with AMOS, (2 ${ }^{\text {nd }}$ Ed). Taylor: Francis Group. 